\title{
Evaluation of Subsite Affinities of Soybean $\beta$-Amylase by Product Analysis
}

\author{
Toshihiko Suganuma, * Masatake OHnishi, Keitaro Hirom \\ and Yuhei MORITA** \\ Department of Food Science and Technology, Faculty of Agriculture, \\ Kyoto University, Sakyo-ku, Kyoto 606, Japan
}

Received October 29, 1979

\begin{abstract}
Subsite affinities of soybean $\beta$-amylase were evaluated by a new method to elucidate the effect of multiple attack. Product analysis of the reducing end-labeled maltooligosaccharides showed that $\mathrm{G}_{6}^{*}$ and $\mathrm{G}_{7}^{*}$ were degraded through the multiple attack pathway, in $0.02 \mathrm{M}$ acetate buffer, $\mathrm{pH} 5.4$ at $25^{\circ} \mathrm{C}$. The apparent first-order rate constants, $\left(k_{0} / K_{m}\right) e_{0}$, for $n$-mer substrates $(n=3-7)$ were obtained from the decrease of substrate followed by paper chromatography under the condition of $[\mathrm{S}] \ll K_{m}$. Using the constants and the cleavage distribution of $\mathrm{G}_{3}^{*}$, the subsite affinities $\left(A_{1}, A_{4}\right.$ and $\left.A_{5}\right)$ of $\beta$-amylase were evaluated. It was revealed that the first subsite of soybean $\beta$-amylase had a larger subsite affinity than any subsites of other amylases so far evaluated. Thus the first subsite seems to play an important role for the characteristic action pattern of this enzyme, namely exclusive maltose-forming action. The frequency of multiple attack decreased as either or both $\mathrm{pH}$ and temperature become unfavorable for enzymic activity.
\end{abstract}

$\beta$-Amylase is found mainly in higher plants. This enzyme has a characteristic exo-type action pattern such that the enzyme attacks the nonreducing terminus of starch or its related substrates with the scission of the penultimate linkage with exclusive formation of $\beta$-maltose. ${ }^{1,2)}$ Many investigators have paid attention to its degradative pattern, including multiple (repetitive) $\operatorname{attack}^{3 \sim 11)}$ : After the initial catalytic reaction, the product remains on the enzyme surface to give a new productive complex, and such subsequent attack may be repeated several times before the enzyme and remaining substrate dissociate. This type of mechanism is found in the action of other amylases on amylose. ${ }^{12 \sim 18)}$

Recently a unified theory was developed to analyze quantitatively the action patterns of various amylases in terms of "subsite affi-

* Present address: Department of Agricultural Chemistry, Faculty of Agriculture, Kagoshima University. Koorimoto, Kagoshima 890, Japan.

** Research Institute for Food Science, Kyoto University, Uji, Kyoto 611, Japan. nities." Subsite affinities are represented as the unitary free energy decrements upon binding of the glucose residue of substrate to individual subsites constituting the active site of an amylase. ${ }^{19 \sim 26)}$ The subsite theory is essentially applicable to all amylase reactions, but slight modification is necessary for enzyme reactions accompanied with the multiple attack and/or the bi-substrate processes such as transglycosylation and condensation, since these factors complicate the meaning of experimentally obtainable rate parameters. In the preceding paper, ${ }^{26)}$ we showed the effect of the bisubstrate processes could be eliminated by using the apparent first order rate constant, $\left(k_{0} / K_{m}\right) e_{0}$, obtainable at sufficiently low substrate concentrations $\left([\mathrm{S}] \ll K_{m}\right)$.

In this paper, we evaluate the subsite affinities of soybean $\beta$-amylase, using the apparent first order rate constants, $\left(k_{0} / K_{m}\right) e_{0}$, obtained from the measurement of the decrease in the starting substrates $\left(\mathrm{G}_{3}-\mathrm{G}_{7}^{* 1}\right)$, so that the effect of the multiple attack may be eliminated.

*1 Abbreviations: $\mathrm{G}_{3}$, maltotriose; $\mathrm{G}_{4}$, maltotetraose: $\mathrm{G}_{5}$, maltopentaose; $\mathrm{G}_{6}$, maltohexaose; $\mathrm{G}_{7}$, maltoheptaose. 


\section{MATERIALS}

Crystalline soybean $\beta$-amylase was prepared from defatted soybean flour (supplied by Honen Seiyu Co. Ltd., Tokyo) according to the method of Morita et al ${ }^{27}$ Two components (components I and II) were obtained. ${ }^{27 \sim 291}$ The concentration of the enzyme was estimated spectrophotometrically, using the value of absorption coefficient, $E_{280 \mathrm{~nm}}^{1 \%}$ of $17.0 \mathrm{~cm}^{-1}$ and the molecular weight of 57,000 , for both components I and II. ${ }^{29)}$ No contamination of $\alpha$-glucosidase was confirmed by using the radioactive maltose as substrate; maltose was not hydrolyzed by sufficiently high concentration of the enzyme preparations to hydrolyze $96.7 \%$ of $\mathrm{G}_{3}$ in a reaction period.

Maltotriose and other maltooligosaccharides labeled in the reducing end glucose unit were prepared with ${ }^{14} \mathrm{C}$ glucose (the Radiochemical Centre, England) and cyclohexaamylose (Hayashibara Biochemical Lavoratories, Inc., Okayama) by means of the coupling reaction of $B$. macerans transglycosylase. ${ }^{301}$ Each labeled oligosaccharide was purified by multi-ascending paper chromatography and re-chromatographed more than once to obtain pure saccharide. The purity of the radioactive maltotriose obtained was $99.76 \%$.

\section{METHODS}

The experimental procedure with the reducing endlabeled maltooligosaccharide to determine the apparent first order rate constant, $\left(k_{0} / K_{m}\right) e_{0}$, is essentially the same as the one in the preceding paper. ${ }^{26)}$ Component $\mathbf{I I}$, which is the major component of soybean $\beta$-amylase was used for this study. The enzyme reaction was performed in a microtube in $0.02 \mathrm{M}$ acetate buffer, $\mathrm{pH} 5.4$, at $25^{\circ} \mathrm{C}$, and was terminated with $0.05 \mathrm{M} \mathrm{NaOH}$ after appropriate time intervals. The reaction products were separated by multiple ascending paper chromatography. ${ }^{31 /}$ After irrigation twice, the strip of paper was cut into segments and their radioactivities were counted for $5 \mathrm{~min}$ with a Packard 3320 liquid scintillation spectrophotometer. The counts were corrected for background and substrate blank.

\section{RESULTS AND DISCUSSION}

Estimation of the rate parameter $\left(k_{0} / K_{m}\right)$ by the product analysis

Figure 1 shows typical examples of the time courses of change in substrate and product saccharides in the degradation of the reducing end-labeled maltohexaose $\mathrm{G}_{6}^{*}$ and maltoheptaose $\mathrm{G}_{7}^{*}$. Both products $\mathrm{G}_{2}^{*}$ and $\mathrm{G}_{4}^{*}$ increased simply in progress of the degradation of $G_{6}^{*}$. The degradation of $G_{7}^{*}$ produced $G_{3}^{*}$ and $\mathrm{G}_{5}^{*}$.

The enzyme cleaved the nonreducing ter-

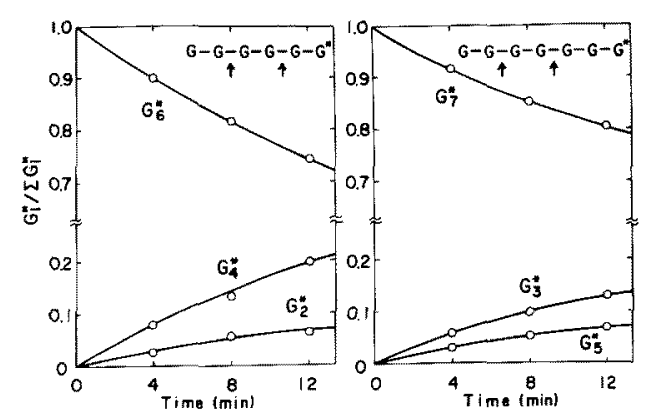

FIG. 1. Time Courses of Degradation of the Reducing End-labeled Maltohexaose $\left(G_{6}^{*}\right)$ (Left) and Maltoheptaose $\left(G_{7}^{*}\right)$ (Right) Catalyzed by Soybean $\beta$ Amylase

The reaction was performed in $0.02 \mathrm{M}$ acetate buffer, $\mathrm{pH}$ 5.4 , at $25^{\circ} \mathrm{C} . e_{0}=3.65 \times 10^{-10} \mathrm{M},\left[\mathrm{G}_{6}\right]_{0}=25 \mu \mathrm{M},\left[\mathrm{G}_{7}\right]_{0}=$ $12 \mu \mathrm{M}$. The radioactivity of each section of paper cut-off is represented as a fraction of the total radioactivity in the reaction mixture taken for analysis.

minus of substrate to produce maltose, as illustrated in Fig. 1. Unless multiple attack (repetitive attack on the same substrate molecule) happened, $\mathrm{G}_{2}^{*}$ would not be produced from $G_{6}^{*}$ before the primary product $G_{4}^{*}$ (produced by the initial attack on $\mathrm{G}_{6}^{*}$ ) accumulates in the reaction system. Since $G_{4}^{*}$ was hydrolyzed more slowly than $\mathrm{G}_{6}^{*}$, time course of $\mathrm{G}_{2}^{*}$ production was thought to have a lag phase. The lag phase, however, was not observed in the time course of $G_{2}^{*}$ production as shown Fig. 1. Thus, the multiple attack is an essential property of action of $\beta$-amylase. The results also indicated that $G_{4}^{*}$, the primary product from $\mathrm{G}_{6}^{*}$, was produced faster than $\mathrm{G}_{2}^{*}$, the secondary product, whereas $\mathrm{G}_{3}^{*}$, the secondary product from $\mathrm{G}_{7}^{*}$, overwhelmed $\mathrm{G}_{5}^{*}$, the primary product (Fig. 1). Smaller substrates than $G_{5}^{*}$ produced single labeled products, respectively. Therefore, the frequency of multiple attack was considered to depend on the degree of polymerization (n) of the substrate.

When the multiple attack mechanism is operating, the following equation should hold;

$$
\mathrm{d}[\mathrm{P}] / \mathrm{d} t=-(\mathrm{d}[\mathrm{S}] / \mathrm{d} t) \times F
$$

where $[\mathrm{P}]$ and $[\mathrm{S}]$ represent molar concentration of maltose produced and that of the 
starting substrate, respectively. $F$ is the frequency of the multiple attack $(F>1)$. Thus the rate measured by the reducing power, which refers to the total molar concentration of the products, $[\mathrm{P}]$, is not equal to the rate of decrease of the starting substrate, [S], that is, $\mathrm{d}[\mathrm{P}] / \mathrm{d} t \neq-\mathrm{d}[\mathrm{S}] / \mathrm{d} t$.

We estimated the real reaction rate by means of measurement of the remaining substrate which was free from the effect of multiple attack. The hydrolytic reaction of the enzyme followed the first-order kinetics, since the reaction was performed under the condition of [S] $\ll K_{m}$. The value of $K_{m}$ estimated by Kato $e t$ $a l .{ }^{32 a}$ was tentatively used. Under this condition, bi-substrate reaction such as transglycosylation or condensation is eliminated. Thus,

$$
\begin{aligned}
-\frac{\mathrm{d}[\mathrm{S}]}{\mathrm{d} t} & =\frac{V_{\max }[\mathrm{S}]}{K_{m}+[\mathrm{S}]} \cong\left(V_{\max } / K_{m}\right)[\mathrm{S}] \\
& =\left(k_{0} / K_{m}\right) e_{0}[\mathrm{~S}]
\end{aligned}
$$

The first-order plot for a starting substrate $\mathrm{G}_{7}^{*}$, where the plot was obtained by the procedure reported elsewhere, ${ }^{26)}$ is shown in Fig. 2. The slope provides us with an apparent first-order rate constant, $\left(k_{0} / K_{m}\right) e_{0}$ for the substrate. The rate parameters of $k_{0} / K_{m}$ for several kinds of substrate obtained by the procedure are summarized in Table I together with the results obtained by Kato et al. ${ }^{32 a)}$ Using partially purified enzyme, they estimated

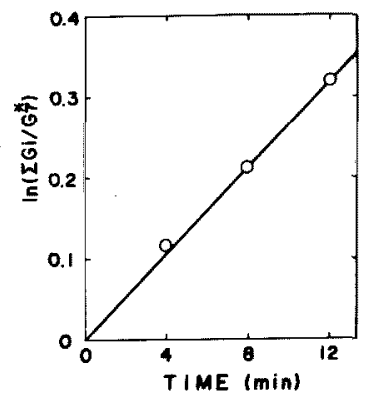

FIG. 2. First-order Plot of Time Course of Hydrolysis of Maltoheptaose by Soybean $\beta$-Amylase.

$e_{0}=3.65 \times 10^{-10} \mathrm{M},\left[\mathrm{G}_{7}\right]_{0}=12 \mu \mathrm{M}, 0.02 \mathrm{M}$ acetate buffer, $\mathrm{pH}$ 5.4 , at $25^{\circ} \mathrm{C}$. The ordinate shows change in the amount of substrate as the logarithm of the ratio of the total radioactivity to the radioactivity of maltoheptaose in the aliquot taken for analysis.

Table I. Dependency of the Rate Parameter $\left(k_{0} / K_{m}\right)$ ON THE DEGREE OF POLYMERIZATION OF SUBSTRATE

(a)

$\begin{array}{lcc}\mathrm{G}_{3} & 2.44 \times 10^{3} & 5.33 \times 10^{2} \\ \mathrm{G}_{4} & 1.70 \times 10^{7} & 7.30 \times 10^{6} \\ \mathrm{G}_{5} & 9.24 \times 10^{7} & 2.07 \times 10^{7} \\ \mathrm{G}_{6} & 7.85 \times 10^{7} & 1.96 \times 10^{7} \\ \mathrm{G}_{7} & 8.36 \times 10^{7} & 7.47 \times 10^{7} \\ \mathrm{G}_{12.5} & - & 7.47 \times 10^{7}\end{array}$

(a) present data; (b) data by M. Kato (32a); dimension, $\min ^{-1} M^{-1}$

the reaction rates for those substrates by measuring the reducing power, which represents the total products; thus their values may have included the influence of multiple attack. In the present study, the value of $k_{0} / K_{m}$ for $\mathrm{G}_{7}$ was nearly equal to that for $G_{5}$, while in the case by Kato et al., a significantly big difference was observed between those for $G_{5}$ and $G_{7}$. The difference in tendency between Kato and the present studies seems to be due to difference in the method of estimating $k_{0} / K_{m}$.

Analysis of cleavage pattern on the reducing endlabeled maltotriose, $G_{3}^{*}$ as the substrate

The cleavage of the end-labeled maltotriose by $\beta$-amylase was performed at the substrate concentration of $0.11 \mathrm{~mm}$. The paper chromatogram of the hydrolysate is shown in Fig. 3, indicating that the radioactive glucose, $G_{1}^{*}$, was the major product from the substrate $G_{3}^{*}$, while only a small amount of radioactive maltose, $G_{2}^{*}$, was also produced. The ratio of the radioactive glucose to the radioactive maltose produced was determined to be about 240 $\left(\left[\mathrm{G}_{1}^{*}\right] /\left[\mathrm{G}_{2}^{*}\right]=240 / 1\right)$. Maltotriose must be bound at the active site of $\beta$-amylase in two productive binding modes, I and II (Fig. 4); $\mathrm{G}_{1}^{*}$ and $\mathrm{G}_{2}^{*}$ are formed corresponding to the mode I and II, respectively. Thus, the present results show that the main productive binding mode of maltotriose is the mode I.

The relative rate of $\mathrm{G}_{1}^{*}$ and $\mathrm{G}_{2}^{*}$ productions, $v_{\mathrm{G}_{1}^{*}} / v_{\mathrm{G}_{2}^{*}}$, is proportional to the ratio of the probabilities of the mode I and II, $P_{\mathrm{I}} / P_{\mathrm{II}}$. 


$$
\frac{v_{\mathrm{G}_{1}^{*}}}{v_{\mathrm{G}_{2}^{*}}}=\frac{\mathrm{d}\left[\mathrm{G}_{1}^{*}\right] / \mathrm{d} t}{\mathrm{~d}\left[\mathrm{G}_{2}^{*}\right] / \mathrm{d} t}=\frac{P_{\mathrm{I}}}{P_{\mathrm{II}}}
$$

According to the subsite theory, ${ }^{19,24)}$ the ratio $P_{\mathrm{I}} / P_{\mathrm{I}}$ is related to the difference between the subsite affinities $\left(A_{i}\right)$ of the two subsites which are not common to the two modes $\left(A_{1}\right.$ and $A_{4}$ in this case),

$$
P_{\mathrm{l}} / P_{\mathrm{Il}}=\exp \left[\left(A_{1}-A_{4}\right) / R T\right]
$$

where $R$ is the gas constant and $T$ is the absolute temperature. Both the productions of $G_{1}^{*}$ and $G_{2}^{*}$ obey the first-order kinetics under the condition of $[\mathrm{S}] \ll K_{m}$. Since the multiple attack is not observed in the case of maltotriose, the following equation is obtained from Eq. 2.

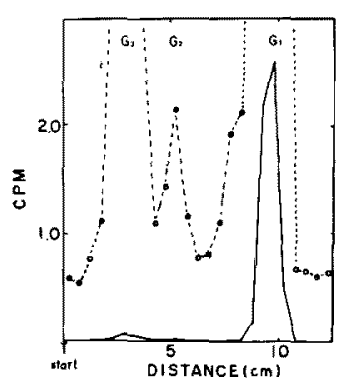

FIG. 3. Chromatogram of $\beta$-Amylase Hydrolysate of the Reducing End-labeled Maltotriose $\left(\mathrm{G}_{3}{ }^{*}\right)$.

Radioactive maltotriose $\left(5.7 \times 10^{5} \mathrm{cpm}\right)$ was used as the substrate. The reaction was performed at $25^{\circ} \mathrm{C}$, in $0.02 \mathrm{M}$ acetate buffer, pH 5.4 , containing $10 \mathrm{~mm}$ mercaptoethanol and $2 \mathrm{mM}$ EDTA. $e_{0}=2.8 \times 10^{-9} \mathrm{M},[\mathrm{S}]=110 \mu \mathrm{M}$. The ordinate shows the radioactivity of the section of the paper cut off. -, $\mathrm{cpm} \times 10^{-4} ;--, \mathrm{cpm} \times 10^{-2}$.

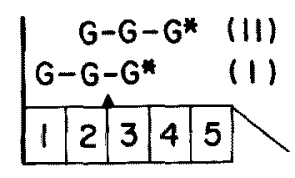

FIG. 4. Schematic Model for Two Possible Productive Binding Modes (I and II) of Maltotriose with $\beta$-Amylase.

$G$ and $G^{*}$ represent unlabeled and labeled glucose residues, respectively. The wedge ( $\boldsymbol{\Delta}$ ) shows the catalytic site of the enzyme. The boxes are the subsites numbered as indicated. The hedge on the left represents the steric hidrance in substrate binding.

$$
\frac{v_{\mathrm{G}_{1}^{*}}}{v_{\mathrm{G}_{2}^{*}}^{*}}=\frac{\mathrm{d}\left[\mathrm{G}_{1}^{*}\right] / \mathrm{d} t}{\mathrm{~d}\left[\mathrm{G}_{2}^{*}\right] / \mathrm{d} t}=\frac{k[\mathrm{~S}]}{k^{\prime}[\mathrm{S}]}=\frac{k}{k^{\prime}}=K(\text { constant })
$$

where $k$ and $k^{\prime}$ represent the first-order rate constants for the productions of $\mathrm{G}_{1}^{*}$ and $\mathrm{G}_{2}^{*}$, respectively.

$$
\mathrm{d}\left[\mathrm{G}_{1}^{*}\right] / \mathrm{d}\left[\mathrm{G}_{2}^{*}\right]=K
$$

Since both concentrations of $\left[G_{1}^{*}\right]$ and $\left[G_{2}^{*}\right]$ are zero at $t=0$,

$$
\left[\mathrm{G}_{1}^{*}\right]=K\left[\mathrm{G}_{2}^{*}\right]
$$

Therefore,

$$
v_{\mathrm{G}_{1}^{*}} / v_{\mathrm{G}_{2}^{*}}^{*}=\left[\mathrm{G}_{1}^{*}\right] /\left[\mathrm{G}_{2}^{*}\right]
$$

Then, $\left(A_{1}-A_{4}\right)$ can be obtained from Eqs. 3 and 4 as follows;

$$
\begin{aligned}
A_{1}-A_{4} & =R T \ln \left(v_{\mathrm{G}_{1}}^{*} / v_{\mathrm{G}_{2}}^{*}\right) \\
& =R T \ln \left(\left[\mathrm{G}_{1}^{*}\right] /\left[\mathrm{G}_{2}^{*}\right]\right)=R T \ln (240 / 1) \\
& =3.2 \mathrm{kcal} / \mathrm{mol} \quad(14 \mathrm{~kJ} / \mathrm{mol})
\end{aligned}
$$

The subsite affinity of the subsite $1, A_{1}$, was estimated to be larger than that of the subsite 4 , $A_{4}$, by $3.2 \mathrm{kcal} / \mathrm{mol}$.

\section{Evaluation of subsite affinities}

As mentioned earlier, $\beta$-amylase is regarded practically to have such a single productive binding mode that the first subsites are occupied by a substrate molecule. According to the subsite theory, rate parameter $k_{0} / K_{m}$ for an $n$-mer substrate is proportional to the association constant for the productive binding mode, which is determined by the subsite affinities of subsites that are covered by the substrate molecule as follows ${ }^{19}$ :

$$
\begin{aligned}
\left(k_{0} / K_{m}\right)_{n} & =k_{\text {int }} K_{n, p} \\
& =0.018 k_{\text {int }} \exp \left(\sum_{i}^{c o v} A_{i} / R T\right)_{n, p}
\end{aligned}
$$

where $k_{\text {int }}$ is the intrinsic rate constant for the hydrolysis of the substrate linkage in a productive complex, which is assumed to be constant irrespective of the degree of polymerization of substrate, $n$, and the mode of productive binding, $p$ (Similar to glucoamylase, $\beta$ - 
amylase can be practically regarded to have single productive binding mode). $K_{n, p}$ represents the association constant of $n$-mer substrate to form the productive ES complex. The summation $\sum_{i} A_{i}$ means that the sum is taken for the subsites occupied by the $n$-mer substrate in the specified binding mode $p$. The factor 0.018 arises from the correction for the change in free energy of mixing upon the binding of $\mathrm{E}$ and $S$, which is common for a bi-molecular association equilibrium $(2.4 \mathrm{kcal} / \mathrm{mol}$ or $10 \mathrm{~kJ} / \mathrm{mol}$ at $25^{\circ} \mathrm{C}$ in aqueous solution ${ }^{33)}$ ).

The rate parameter $k_{0} / K_{m}$ increased with $n$, when $n<5$, and it became almost constant when $n \geqq 5$ (see Table I). These facts lead to the conclusion that soybean $\beta$-amylase has 5 subsites.

Then, in the manner similar to that used for glucoamylase, ${ }^{19)}$ the fourth and the fifth subsite affinities of $\beta$-amylase can be evaluated using the $k_{0} / K_{m}$ values for maltooligosaccharides, as follows;
Therefore,

$$
\begin{aligned}
A_{5} & =R T \ln \frac{\left(k_{0} / K_{m}\right)_{5}}{\left(k_{0} / K_{m}\right)_{4}}=R T \ln \frac{1.26 \times 10^{8}}{2.32 \times 10^{7}} \\
& =1.0 \mathrm{kcal} / \mathrm{mol} \\
& (=4.2 \mathrm{~kJ} / \mathrm{mol}) \\
A_{4} & =R T \ln \frac{\left(k_{0} / K_{m}\right)_{4}}{\left(k_{0} / K_{m}\right)_{3}}=R T \ln \frac{2.32 \times 10^{7}}{3.33 \times 10^{3}} \\
& =5.2 \mathrm{kcal} / \mathrm{mol} \\
( & =21.8 \mathrm{~kJ} / \mathrm{mol})
\end{aligned}
$$

Thus, the ratio of $k_{0} / K_{m}$ value for $n$-mer to that of $(n-1)$-mer substrate permits us to evaluate the subsite affinity of the $n$-th subsite which is occupied by the longer subsite alone.

From the cleavage distribution of $G_{3}^{*}$, i.e., the probabilities of cleavage at respective glycosidic bond, the relative value of the first subsite affinity to the fourth subsite affinity was estimated to be $3.2 \mathrm{kcal} / \mathrm{mol}(14 \mathrm{~kJ} / \mathrm{mol})$ as described in the preceding section. Since $A_{4}$ is

$$
\frac{\left(k_{0} / K_{m}\right)_{5}}{\left(k_{0} / K_{m}\right)_{4}}=\frac{0.018 k_{\mathrm{int}} \exp \left[\left(A_{1}+A_{2}+A_{3}+A_{4}+A_{5}\right) / R T\right]}{0.018 k_{\mathrm{int}} \exp \left[\left(A_{1}+A_{2}+A_{3}+A_{4}\right) / R T\right]}=\exp \left(A_{5} / R T\right)
$$

$5.2 \mathrm{kcal} / \mathrm{mol}(21.8 \mathrm{~kJ} / \mathrm{mol})$, the value of $A_{1}$ is estimated to be $8.4 \mathrm{kcal} / \mathrm{mol}(35.8 \mathrm{~kJ} / \mathrm{mol})$. The subsite affinities thus obtained are shown in a histogram in Fig. 5. $\beta$-Amylase has 5 subsites as described above, and the catalytic site is located between the second and the third subsites as expected from its action pattern of exclusive

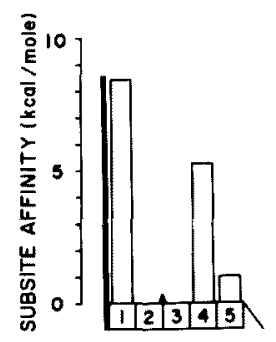

Fig. 5. Histogram of Subsite Structure of Soybean $\beta$ Amylase.

The wedge ( $\boldsymbol{\Delta}$ ) shows the catalytic site of the enzyme. The boxes represent the subsites numbered as indicated. The hedge on the left shows the steric hidrance in substrate binding.
TABLE II. SUbsite AfFinities of SOYBEAN $\beta$-AMYLASE

\begin{tabular}{rrrrl}
\hline \multicolumn{1}{c}{$A_{1}$} & $A_{2}+A_{3}$ & \multicolumn{1}{c}{$A_{4}$} & \multicolumn{1}{l}{$A_{5}$} & \\
\hline 8.4 & - & 5.2 & 1.0 & $\mathrm{kcal} / \mathrm{mol}$ \\
35.8 & - & 21.8 & 4.2 & $\mathrm{~kJ} / \mathrm{mol}$ \\
\hline
\end{tabular}

formation of maltose. The two subsites adjacent to the catalytic site cannot be evaluted for these affinities by this method. One of the noticeable characteristics of $\beta$-amylase is that the first subsite with subsite affinity of 8.4 $\mathrm{kcal} / \mathrm{mol}(35.8 \mathrm{~kJ} / \mathrm{mol})$ must be responsible for the exclusive maltose-forming ability of $\beta$ amylase (the binding mode I should occur much easier than the binding mode II; see Figs. 3 and 4).

Effect of $p H$ and temperature on multiple attack The influence of some effectors on the frequency of multiple attack was investigated. The 
enzyme reaction were performed at various values of $\mathrm{pH}$ and temperature. Experiments for $\mathrm{pH}$ as variable were performed at $25^{\circ} \mathrm{C}$, and those for temperature at $\mathrm{pH}$ 5.4. For this purpose, the reducing end-labeled maltoheptaose was used as substrate, which was hydrolyzed easily into labeled maltotriose by multiple attack of $\beta$-amylase. As seen from Fig. 6 , the frequency of multiple attack, which is expressed in the ratio of labeled maltotriose to labeled maltopentaose, $\mathrm{G}_{3}^{*} / \mathrm{G}_{5}^{*}$, decreases with decrease in temperature and with departure from the optimum $\mathrm{pH}$. Thus the frequency of the multiple attack markedly depended on temperature and $\mathrm{pH}$ of the reaction medium, in addition to the degree of polymerization of substrate.

Many reserch groups have so far estimated the frequency of multiple attack for the reactions of $\beta$-amylase, ${ }^{3 \sim 11,16)} \alpha$-amylases from porcine pancreas, ${ }^{12,13 \text { f }}$ human saliva, ${ }^{12,16 \text { ) }}$ Aspergillus oryzae, ${ }^{12,18}$ Bacillus subtilis (liquefying), ${ }^{16)}$ malted rye, ${ }^{14)}$ oats, ${ }^{14)}$ wheat ${ }^{14 \text { ) }}$ and soybean Z-enzyme. ${ }^{15)}$ Methods employed are as follows: (i) product analysis, ${ }^{9 \sim 11,13,18}$ (ii) shift in maximum wavelength of the blue value, ${ }^{10)}$ (iii) the relationship between the blue value and the reducing value, ${ }^{12)}$ (iv) the relationship between fluorescence of 6-ptoluidinylnaphthalene-2-sulfonate (TNS) and the reducing value, ${ }^{17)}$ and $(\mathrm{v})$ the relationship between $\overline{D P}_{w}{ }^{2}$ estimated by viscosity and $\overline{D P}_{n}{ }^{* 2}$ from enzymic assay. ${ }^{16)}$ The degree of multiple attack of various amylases have been found to decrease at unfavorable $\mathrm{pH}$ or temperature, ${ }^{6,11 \sim 13,17)}$ by chemical modification of the enzyme, ${ }^{77}$ in the presence of glycerol ${ }^{16)}$ and with an uncompetitive inhibitor, methyl $\alpha$ glucoside, ${ }^{7)}$ but not be affected by the addition of maltose, ${ }^{7}$ cyclodextrin, ${ }^{7)}$ and by the elimination of $\mathrm{Cl}^{-}$ion (for porcine pancreatic $\alpha$ amylase. $^{17)}$

The present study has revealed that soybean $\beta$-amylase exhibits multiple attack on $\mathrm{G}_{7}$ and $\mathrm{G}_{6}$ from the nonreducing termini. On the other

*2 $\overline{D P}_{w,}$ the weight average degree of polymerization, $\overline{D P}_{n}$; the number average degree of polymerization.

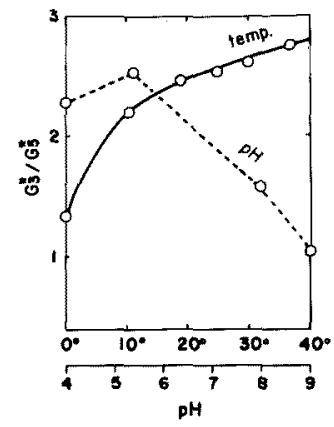

FlG. 6. Dependency of Multiple Attack on Temperature and $\mathrm{pH}$ in the Reaction of Soybean $\beta$-Amylase with the Reducing End-labeled Maltoheptaose $\left(G_{7}^{*}\right)$.

The reactions were performed in $0.1 \mathrm{~m}$ acetate buffer $(\mathrm{pH}$ 4.0 and 5.4$)$, in $0.1 \mathrm{M}$ Tris- $\mathrm{HCl}$ buffer $(\mathrm{pH} 8.0)$ and $0.1 \mathrm{M}$ Glycine-NaOH buffer ( $\mathrm{pH} \mathrm{9.0)}$ ). The ordinate shows the ratio of the secondary product $\left(G_{3}^{*}\right)$ to the primary product $\left(\mathrm{G}_{5}^{*}\right)$ as a measure for the degree of multiple attack. $e_{0}=6.9 \times 10^{-10} \mathrm{M},[\mathrm{S}]=9 \mu \mathrm{M}$.

hand, with $\mathrm{G}_{5}$ and shorter maltooligosaccharides, the enzyme performs multi-chain attack, in which the enzyme removes single units (maltose) in completely random fashion from all available polymer ends. ${ }^{97}$ The ratio of the secondary product to the primary product was $2.6\left(=\mathrm{G}_{3}^{*} / \mathrm{G}_{5}^{*}\right)$ and $0.3\left(=\mathrm{G}_{2}^{*} / \mathrm{G}_{4}^{*}\right)$ for $\mathrm{G}_{7}^{*}$ and $\mathrm{G}_{6}^{*}$, respectively $\left(\mathrm{pH} 5.4,25^{\circ} \mathrm{C}\right.$ ). Our result for maltoheptaose was not consistent with that reported by French et al.; they reported that maltopentaose did not accumulate in significant amount during the enzyme digests of maltoheptaose. ${ }^{51}$ The disagreement might be due, in part at least, to the methods of product analysis used; their chromatographic determination may have been not sensitive enough. However, other results that the frequency of multiple attack decreased at unfavorable $\mathrm{pH}$ or temperature ${ }^{6)}$ were reconfirmed by the present study.

\section{REFERENCES}

1) R. Kuhn, Ber., 57B, 1965 (1924).

2) J. A. Thoma and D. E. Koshland, Jr, J. Am. Chem. Soc, 82, 3329 (1960).

3) F. C. Cleveland and R. W. Kerr, Cereal. Chem., 25, 133 (1948); R. W. Kerr, Nature, 164, 757(1949); R.W. 
Kerr and F. C. Cleveland, J. Am. Chem. Soc., 73, 2421 (1951); R. W. Kerr and F. C. Cleveland, J. Am. Chem. Soc., 74, 4036 (1952).

4) M. A. Swanson, J. Biol. Chem, 172, 805(1948); M. A. Swanson and C. F. Cori, J. Biol. Chem., 172, 815 (1948); M. A. Swanson, J. Biol. Chem., 172, 825 (1948).

5) D. French, M. L. Levine, J. H. Pazur and E. Norberg, J. Am. Chem. Soc. 72, 1746 (1950).

6) D. French, D. W. Knapp and J. H. Pazur, J. Am. Chem. Soc., 72, 1866 (1950).

7) J. E. Spradlin, Doctor's Thesis (Indiana University) (1970).

8) E. Laszlo, J. Hollo and B. Bankey, Die Stärke, 25, 417 (1973).

9) J. M. Bailey and D. French, J. Biol. Chem., 226, 1 (1957).

10) J. M. Bailey and W. J. Whelan, Biochem. J., 67, 540 (1957)

11) D. French and R. W. Younguist, Die Stärke, 15, 425 (1963).

12) J. F. Robyt and D. French, Arch. Biochem. Biophys., 122, 8 (1967).

13) J. F. Robyt and D. French, Arch. Biochem. Biophys., 138, $662(1970)$.

14) C. T. Greenwood and E. A. Milne, Die Stärke, 20, 101 (1968).

15) C. T. Greenwood, A. W. MacGregor and E. A. Milne, Carbohyd. Res., 1, 303 (1965).

16) W. Banks, C. T. Greenwood and K. M. Khan, Carbohyd. Res., 12, 79 (1970).

17) H. Kondo, H. Nakatani, K. Hiromi and R. Matsuno, J. Biochem., 84, 403 (1978).

18) J. D. Allen and J. A. Thoma, Carbohyd. Res., 61, 377 (1978).

19) a) K. Hiromi, Biochem. Biophys. Res. Commun., 40, 1
(1970); b) K. Hiromi, Y. Nitta, C. Numata and S. Ono, Biochim. Biophys, Acta, 302, 362 (1973).

20) Y. Nitta, M. Mizushima, K. Hiromi and S. Ono, $J$. Biochem., 69, 567 (1971).

21) S. Iwasa, H. Aoshima, K. Hiromi and H. Hatano, J. Biochem., 75, 969 (1974).

22) T. Shibaoka, K. Miyano and T. Watanabe, $J$. Biochem., 76, 475 (1974).

23) K. Miyano, Master's Thesis (University of Osaka Prefecture) (1974)

24) a) J. A. Thoma, C. Brothers and J. Spradlin, Biochemistry, 9, 1768(1970); b) J. A. Thoma, G. V. K. Rao, C. Brothers, J. Spradlin and L. H. Li, J. Biol. Chem., 246, 5621 (1961).

25) a) J. D. Allen and J. A. Thoma, Biochem. J., 159, 105 (1967); b) J. D. Allen and J. A. Thoma, Biochem. J., 159, $121(1976)$; c) J. A. Thoma and J. D. Allen, Carbohyd. Res., 48, 105 (1976)

26) T. Suganuma, R. Matsuno, M. Ohnishi and K. Hiromi, J. Biochem., 84, 293 (1978).

27) Y. Morita, S. Aibara, H. Yamashita, F. Yagi, T. Suganuma and K. Hiromi, J. Biochem., 77, 343 (1975).

28) T. Suganuma, Master's Thesis (Kyoto University) (1974).

29) F. Yagi, Doctor's Thesis (Kyoto University) (1977).

30) J. H. Pazur, J. Am. Chem. Soc., 77, 1015 (1955).

31) D. French, J. L. Mancusi, M. Abdullah and G. L. Brammer, J. Chromatog., 19, 445 (1965).

32) a) M. Kato, Master's Thesis (Kyoto University) (1973); b) M. Kato, K. Hiromi and Y. Morita, J. Biochem., 75, 563 (1974).

33) W. Kauzmann, "Advance in Protein Chemistry," Vol. 14, Academic Press, New York and London, 1959 , p. 1. 